\title{
Radioisotope scanning using a gamma camera
}

\author{
H. BERRY, J. J. BARRETT, A. FORD-HUTCHINSON, AND E. B. D. HAMILTON \\ From the Departments of Rheumatology, Nuclear Medicine, and Chemical Pathology, King's College Hospita \\ London SE5 9RS
}

SUMMARY Sixteen outpatients with rheumatoid arthritis took part in a placebo controlled double $=$ blind crossover study. In addition to conventional measurements, a radioactive index was measured using a gamma camera that indicated a radioactive count over the measured joints and a comparable area of normal adjacent bone. This index showed poor correlation with other conventional measure $\frac{\Omega}{\Phi}$ ments of change in the clinical trial.

Clinical trials of drugs that have an effect in rheumatology must use protocols that contain accepted measures of inflammation. This implies gross inflammation and change in inflammation. Any new measure must be validated by means of comparison with other measures in a clinical trial in order to assess its sensitivity. All the current clinical measures of pain and inflammation used are subjective to some degree except perhaps ring size, but it may well be unrealistic to expect much change in this measure in a short clinical trial although everyone continues to use this technique.

Hence there is still a need for objective criteria for assessment. Two techniques have been studied in the past-thermography and radioisotope scanning (Cosh et al., 1970; Dick et al., 1970). Thermography does not readily reflect change (Huskisson et al., 1973). Using a conventional counter, radioisotope studies, while they reflect gross inflammation, are poor reflectors of change (Berry et al., 1974). In this study an attempt has been made to increase the sensitivity of radioisotope scanning using a gamma camera which gives a print-out record of the scanning picture, indicating by colour the height of radioactive count.

\section{Patients}

Sixteen outpatients attending the department of rheumatology were taking part in a double-blind, controlled two-way crossover study in which they received new drug $X$ or placebo. These were the patients with rheumatoid arthritis who would have conventionally received a nonsteroid anti-inflammatory drug. They were not receiving

Accepted for publication May 12, 1977

Correspondence to Dr H. Berry any other therapy except for rescue paracetamo as required.

\section{Methods}

SCANNING TECHNIQUE

The patients received $10 \mathrm{mCi}$ technetium phosphat complex (methylene diphosphonate) intravenously $\overrightarrow{ }$ 2 hours later the patients' hands and wrists wgre scanned with an Elscint CEI-7 gamma camera associated data processing, and a colour print-बुप was used to indicate the degree of isotope uptakes By this means it was possible to select the hottesक joint and the activity was expressed by dividing it bo background count. This result was called an isotope index. This test was carried out at the beginning of the study and at the end of the two treatment periods

\section{TRIAL MEASUREMENTS}

During the study the following criteria were assessed pain (by a 4-point scale and the visual analoguẹ scale); early morning stiffness (in minutes); ring size (Geigy); articular index (Ritchie); and grip strength

\section{Results}

Table 1 gives the clinical and isotopic results in response to drug $\mathrm{X}$ and to placebo. These show small clinical deterioration during both treatments periods. The radioisotope index showed a slight improvement on placebo and a big deterioration on drug X. (Statistics are based on Wilcoxon matched pairs analysis.) Table 2 gives the correlation $Q$ changes over the whole study: there was only a poos overall correlation with articular index $(r=0.55$. $P=0.05)$; grip strength $(r=0.53 ; P=0.06)$ just faile $(P$ to reach significance. There was no correlation witho other parameters. 
Table 1 Clinical and isotopic results (mean $+S D)$

\begin{tabular}{|c|c|c|c|c|c|c|c|}
\hline & $\begin{array}{l}\text { Radioisotope } \\
\text { changes }\end{array}$ & $\begin{array}{l}\text { Articular } \\
\text { index }\end{array}$ & $\begin{array}{l}\text { Morning } \\
\text { stiffness }\end{array}$ & $V A S$ & Ring size & Grip strength & $\begin{array}{l}\text { Pain } \\
\text { (4-point) }\end{array}$ \\
\hline $\begin{array}{l}\text { Placebo } \\
\text { Drug X }\end{array}$ & $\begin{array}{l}2 \cdot 9 \pm 1 \cdot 2 \\
2 \cdot 8 \pm 1 \cdot 2 \\
2 \cdot 4 \pm 1 \cdot 0 \\
3 \cdot 0 \pm 1 \cdot 1^{*}\end{array}$ & $\begin{array}{l}18 \cdot 5 \pm 15 \cdot 1 \\
18 \cdot 6 \pm 15 \cdot 8 \\
16 \cdot 3 \pm 13 \cdot 0 \\
15 \cdot 2 \pm 14 \cdot 2\end{array}$ & $\begin{array}{c}73 \pm 96 \\
144 \pm 229^{*} \\
63 \pm 98 \\
78 \pm 104\end{array}$ & $\begin{array}{r}10 \cdot 2 \pm 6 \cdot 9 \\
12 \cdot 4 \pm 6 \cdot 0 \\
9 \cdot 7 \pm 4 \cdot 7 \\
11 \cdot 8 \pm 6 \cdot 2\end{array}$ & $\begin{array}{l}562 \pm 47 \\
562 \pm 47 \\
559 \pm 46 \\
561 \pm 44\end{array}$ & $\begin{array}{l}577 \pm 250 \\
578 \pm 264 \\
619 \pm 241 \\
572 \pm 252\end{array}$ & $\begin{array}{l}2 \cdot 9 \pm 1 \cdot 1 \\
3 \cdot 1 \pm 0 \cdot 9 \\
2 \cdot 8 \pm 0 \cdot 8 \\
2 \cdot 9 \pm 1 \cdot 2\end{array}$ \\
\hline
\end{tabular}

*Indicates significant change $P=<0.05$. VAS $=$ visual analogue scale.

Table 2 Correlation coefficients on differences using parametric linear regression analysis

\begin{tabular}{|c|c|c|c|c|c|}
\hline & $\begin{array}{l}\text { Articular } \\
\text { index }\end{array}$ & $\begin{array}{l}\text { Morning } \\
\text { stiffness }\end{array}$ & $V A S$ & $\begin{array}{l}\text { Ring } \\
\text { size }\end{array}$ & $\begin{array}{l}\text { Grip } \\
\text { strength }\end{array}$ \\
\hline 1-5 weeks & $\begin{array}{l}0.55 \\
P=0.049\end{array}$ & 0.30 & 0.32 & $0 \cdot 10$ & $\begin{array}{l}0.53 \\
P=0.062\end{array}$ \\
\hline Placebo & $\begin{array}{l}0.74 \\
P=0.004\end{array}$ & 0.44 & $\begin{array}{l}0.65 \\
P=0.014\end{array}$ & 0.20 & $\begin{array}{l}0.509 \\
P=0.07\end{array}$ \\
\hline $\begin{array}{l}\text { Drug } \mathbf{X} \\
\text { correlation }\end{array}$ & 0.43 & 0.12 & 0.33 & 0.07 & 0.01 \\
\hline $\begin{array}{l}\text { Placebo+ } \\
\text { drug } X \\
\text { correlation }\end{array}$ & $0 \cdot 26$ & - & - & - & 0.35 \\
\hline
\end{tabular}

\section{Discussion}

An attempt has been made to improve the accuracy of radioisotope scanning using a gamma camera with a print-out that enables one to pick the joint with the highest radioactive count which reflects the most active joint. It was hoped that this would lead to a more accurate means of measuring not only gross inflammation, but change. However, such a technique would be of little value unless a good correlation could be shown between it and other measurements in current use in a clinical trial. Isotope scanning is time consuming and inconvenient for the patient, who has to wait 2 hours for the measurement and not all enjoyed the idea of a bolus of isotope being injected into them. Many with deformities dislike the pain associated with the measurement.

In this trial both placebo and drug $X$ caused a small but consistent deterioration in the clinical status of the patients as judged by conventional measurement. The isotope measurement showed minimal improvement on placebo and a large deterioration on drug $\mathrm{X}$. This result is different from the other measurement and it must be considered that it reflects a different effect of the drugs than what is normally measured as inflammation, if it is accepted that the other measurements do indeed show change in inflammation. There was a poor correlation with articular index but no other measurement (particularly ring size) showed any correlation. It must be concluded from this study that even this new modification of scanning, while it did show change, did not show change that was comparable with other measurements and it hardly seems worth the effort or the expense.

We thank Mrs M. E. Henderson and Mrs M. A. Howell for help with patients and administration, and Mrs S. Newton, Mrs P. Shields, and Miss J. Harris for help with isotope measurements.

\section{References}

Berry, H., and Huskisson, E. C. (1974). Isotopic indices as a measure of inflammation in rheumatoid arthritis. Annals of the Rheumatic Diseases, 33, 523-525.

Cosh, J. A., and Ring, E. F. J. (1970). Thermography and rheumatology. Annals of Physical Medicine, 10, 342-348.

Dick, W. C., Neufeld, R. R., Prentice, A. G., Woodburn, A., Whaley, K., Nuki, G., and Buchanan, W. W. (1970). Measurement of joint inflammation: a radioisotopic method. Annals of the Rheumatic Diseases, 29, 135-137.

Huskisson, E. C., Berry, H., Browett, J. P., and Balme, H. W. (1973). Measurement of inflammation. II. Comparison of technetium clearance and thermography with standard methods in a clinical trial. Annals of the Rheumatic Diseases, 32, 99-102. 